\title{
Integrating Cultural Change Management Program with Smart Workplace Transformation and Refurbishment Project Schedule
}

\author{
Sefik Emre Ulukan \\ Faculty of Engineering and Architecture, Istanbul Rumeli University, Istanbul, Turkey
}

Received July 22, 2020; Revised August 12, 2020; Accepted August 20, 2020

\section{Cite This Paper in the following Citation Styles}

(a): [1] Sefik Emre Ulukan, "Integrating Cultural Change Management Program with Smart Workplace Transformation and Refurbishment Project Schedule," Civil Engineering and Architecture, Vol. 8, No. 5, pp. 847 - 859, 2020. DOI: 10.13189/cea.2020.080512.

(b): Sefik Emre Ulukan (2020). Integrating Cultural Change Management Program with Smart Workplace Transformation and Refurbishment Project Schedule. Civil Engineering and Architecture, 8(5), 847 - 859. DOI: 10.13189/cea.2020.080512.

Copyright $\bigcirc 2020$ by authors, all rights reserved. Authors agree that this article remains permanently open access under the terms of the Creative Commons Attribution License 4.0 International License

\begin{abstract}
Amongst the current trends in commercial real estate and workplace solutions sector, smart, agile, or digital workplaces that provide flexible and smart working environments have become more important and preferred solution. Globally many companies have been transforming their workplaces into agile workplaces to exploit the benefits including, but not limited to reducing real estate footprint, sustainable \& energy efficient operations, improving employee motivation \& efficiency, and therefore reducing operational costs. The workplace transformation has a significant impact on employee performance and engagement due to the cultural change it brings along. This cultural change must be well managed across all phases of the project to ensure the success of the workplace transformation. This success criterion is an important performance indicator which, is generally measured as user experience upon completion of the project. To effectively manage this process, cultural change management activities should be integrated with the project, design \& construction schedule and linked with the project activities. The objective of this research is to provide a framework program for the cultural change management activities that need to be managed as part of the office transformation and refurbishment projects and integrating them with the project schedule. A focus group study method has been conducted to achieve the objectives of the study. Detailed findings, key change management activities and the framework program have been provided in this paper.
\end{abstract}

Keywords Office Design and Construction, Project Management, Cultural Change Management, Workplace Design and Transformation, Project Program, Smart Office, Digital Workplace, Agile Workplace

\section{Introduction}

Over the last 20 years, there has been a rapid and substantial change in the way that the employees work and the way that the organizations conduct their business. Major developments in technology and the economy had a significant impact on this change. As the work style evolves and changes, workplaces also evolve to accommodate these changes. Especially with the rapid development of technology and global concerns such as economy, environment and sustainability have enabled the development of a new type of workplace that is flexible, agile, productive, user friendly, technological and smart. Businesses started realizing the advantages and importance of transforming the workplaces into an environment that reflects technologies, new \& modern work styles and user preferences such as collaboration culture [1].

The evolution of the workplace and work culture has brought several challenges, concerns and risks related with the human factor due to the major change it involves; such as risks related with the end-user satisfaction from project 
management success point of view, and productivity issues from a business success point of view.

When a Smart Workplace Transformation Project is being executed, the project manager and the organization should take the impact of the changes in the work environment, work model and organizational culture into account, to ensure the transformation project can be successfully completed. To manage and deliver the projects with the highest user satisfaction, workplace transformation project phases can be supported and improved by the implementation of cultural change management which also eliminates or reduces the associated risks.

\section{The Objective of the Study}

The objective of this study is to integrate the change management activities with the Smart Workplace Transformation Project.

The study focuses on the integration of 'Change Management' activities such as work pattern surveys, workshops, training sessions with the smart workplace project management process, rather than the type of technologies utilized to transform a traditional office into a digital or a smart workplace such as room finding \& scheduling system, smart building management system, etc.

\section{Methods}

To achieve the objectives of the study, the evolution and the need for smart workplaces have been reviewed, benefits of the smart workplaces have been summarized, the need for the cultural change management program has been discussed and integration of the change management program with the project program has been achieved by conducting the focus group method. Finally, the outcomes of the study have been summarized in the conclusion section of this study.

\subsection{Agile, Digital or Smart Workplace}

In one of the pioneering researches [2] on the evolution and the future of the workplace, the agile workplace has been defined as a workplace "that is constantly transforming, adjusting and responding to organizational learning" [3]. Bell and Joroff [3] also pointed out that, agility in this context means continuous improvement of the work and associated infrastructure, not only the usage of the technology or the physical environment i.e. the building itself.

This workplace transformation and evolution have been significantly impacted by various factors, such as the needs and the behavioral differences of the generations like millennials and generation X. This human factor has acted as a catalyst over the evolution of the workplace. Over the last 2 decades, a vast number of research and studies have been conducted to identify the behaviors of each generation group and how to adapt the workplace to meet with the needs of different generations. Some of the researches focused on millennials, considering that the millennial workforce was anticipated to reach up to $50 \%$ of the workforce by 2020 [4], which led the designers and businesses to put more focus and priority on adapting the workplace to meeting the needs of the millennial workforce. On the other hand, recently there are arguments against this trend claiming that the workplace should be designed for all generations [5], not just for millennials or upcoming new generations. These studies highlight the importance of designing the workplace in a way that drives the interaction and knowledge transfer between the generations to enhance the productivity of the workforce.

As the Industrial Age has transitioned into the Digital Age, the technology element of the agile workplace has developed even more rapidly. While 'Agile Office' term has been commonly used by the academic world and industry, 'Digital Workplace' and 'Smart Workplace' concept or terminology has also started being used for describing 'digitally and technologically enhanced agile workplaces'. This is mainly due to the breakthrough developments in the wireless communication technologies, digitalization of documents and processes, and developments in collaboration tools and technologies such as, high tech audio-visual tools, internet of things as well as intelligent systems \& equipment such as Smart Building Management Systems, that control the building in a way to provide a functional and comfortable office environment, which in turn improves the employee experience. Utilization of these smart technological tools and equipment, together with the agile workplace principles led to the design of workplaces being transformed into digital or smart workplaces.

'Digital Workplace' term is typically used to describe the workplace as a set of tools that are transforming towards a digital environment. Deloitte [6] defines the DWP as - "The digital workplace encompasses all the technologies people use to get work done in today's workplace - both the ones in operation and the ones yet to be implemented". Following this definition, they refer to tools \& technologies such as HR and business applications, instant messaging and emails, social media and virtual meeting tools. Robertson [7] on the other hand, widens the definition of digital workplace as 'holistic set of tools, platforms, and environments for work, delivering in a coherent, usable and productive way' by adding the 'environment' into the description. In several research studies, authors such as Bakar et al [8] and Williams \& Schubert [9] generally focused on the technology part of the digital workplace as some of the technology companies and software developers are using this term to describe their products or services such as IBM [10], Microsoft [11] and many others. Therefore, 'Digital Workplace' term may 
be confused with technology-based work platforms, products or services, in other words, the software and application-based solutions. Perhaps 'Smart Workplace' would be a better way to describe the technologically enhanced agile offices as it refers to the agility of the physical workplace, efficiency-driven processes and extensive use of smart and highly developed technology.

Regardless of which terminology is used, in a broader context, a smart workplace describes not only some high-tech tools or systems, but a holistic perception of flexible, adaptable, technologically enhanced work environments and processes that promotes productivity, collaboration and innovation.

\subsection{Benefits of Smart Workplaces}

Economic developments over the last 30 years have given rise to the emergence of ideas and initiatives, such as environmentalism, sustainability and cost-efficiency, to name a few, which have contributed to the acceleration of the workplace evolution. This evolution and transformation have not only enabled workplaces to become more efficient and productive, but also helped with the introduction of a new type of business and workplace models such as co-located offices where several different companies share the same office or common parts of the office, and where the workplace is designed to support maximum agility and utilization of technology. While the workplace and technology were evolving and transforming into a new model, these developments have encouraged many businesses to start harnessing the benefits of agile \& smart workplaces. Gartner's research [3] - one of the earliest comprehensive studies in this area - pointed out that some of the multinational companies have already started transforming their offices in the late 1990s and early 2000s.

While many of the technology and multinational companies quickly adapted and implemented the agile/digital/smart workplace designs and standards, some industries or companies haven't shown the same level of willingness or agility to implement the new smart workplace concept due to various different reasons such as, financial status, culture or size of the company. However, more \& more companies are now realizing the benefits of the agile/digital/smart workplaces, where it becomes a viable business case, especially linked with corporate responsibilities and ideals such as sustainability, environment, productivity and profitability. Benefits of smart workplace include;

- Increased employee productivity [12]

- Increased employee satisfaction [13]

- $\quad$ Talent Retention \& Talent Attraction [14]

- Improved employee motivation and engagement [15]

- Increased efficiency by easy access to information and retaining company know-how resulting with significant cost savings and increased profits $[16,17]$
- Footprint reduction \& sustainability as a result of the optimized space as well as fewer building materials and less initial capital investment

- Cost savings from the lease, maintenance and operational costs

- Increased health and wellbeing and reduced absenteeism by flexible working and working from home [18]

- Improved processes and employee skills by using digital tools and high-tech equipment which also boosts creativity \& innovation

- Better customer service and client satisfaction by highly engaged and motivated employees

According to the studies by Deloitte [6], Avanade [17], Van der Voordt [19], further potential benefits can be summarised as;

- Higher problem-solving capacity

- Positive image for the employer

- Improved accessibility

- Better teamwork

- Breaking down silos in the organization by collaboration

While the majority of the studies focus on digital technologies needed for creating a digital workplace, it is also equally important to provide necessary physical infrastructure, environment and 'look and feel' for the smart workplaces. This could be achieved with an effective 'smart workplace design' and an effective 'project management' that, harmonize all those technological and physical elements as an integral part of the workplace.

\subsection{Cultural Change Management for Smart Office Transformation}

While the work and the workplace are transforming, the workforce is also changing. As baby boomers and generation $\mathrm{X}$ are retiring, millennials are taking over the majority in the workforce. According to a report by Pew Research Center [20] based on the US Labor Force statistics, millennials have become the largest generation in the US workforce in 2016 by reaching up to $56 \%$. This transformation comes with challenges. The major challenge is that organizations and people cannot change as quickly as technology or the workplace.

The differences between the generations such as, the level of skills and knowledge and familiarity with the technology or the way of doing business, create difficulty with developing a workplace design suitable for a multi-generational workforce. This difficulty significantly increases during workplace transformations. Employees may have a different level of interests, concerns or hesitations for the upcoming changes. In addition to the emotional challenges of employees, a smart office transformation requires - time, a major cultural change to accommodate all the changes in the way of conducting 
business, the technologies used in the workplace and finally, how the people collaborate. Employees are expected to develop new skills while they are coping with emotional stress and this is where Change Management comes into play.

Figure 1 represents the Change Curve model developed by Elisabeth Kubler-Ross [21] which illustrates the emotional reaction of people upon experiencing a life-changing event. Once the change starts, then the frustration and depression cause a major plunge of performance and competence within the organization due to the emotional reaction that the employees experience.

To avoid or reduce the impact of the negative emotional reaction that employees experience when they hear about the upcoming change i.e. the workplace transformation, a change management process needs to be implemented. Change management helps with the simultaneous development and implementation of the new work processes, necessary skills, technological tools, physical environment and the new work culture needed to make a productive start in the new workplace.

One of the critical success factors of the smart workplace transformation project is to achieve maximum employee experience and satisfaction at the end of the transition. Therefore, employee's engagement, contribution, collaboration and buy-in are vital for a successful implementation. This can be also achieved by the change management process.
Prosci [22] defines change management as 'processes, tools and techniques to manage the people side of the change to achieve its required business outcomes'. It is about managing employee engagement and adopting organizational changes in a systematic way. A common method used for organizational change management is ADKAR model which is an acronym for each milestone of the process, i.e. "Awareness, Desire, Knowledge, Ability and Reinforce", developed by Jeff Hiatt at Prosci. Hiatt \& Creasey [23] define ADKAR method as a model framework to look into managing individual changes and individual transitions. As the smart workplace transformation is more than just an organizational change, it needs to be integrated with the phases of the transformation program and customized to address the challenges arising from a complete change of the work environment. Therefore, the 'workplace cultural change management' efforts should be integrated with workplace transformation project processes and phases.

For this purpose, 5 milestones of ADKAR change management model have been integrated and overlapped with the 5 basic phases of a workplace transformation and fit-out project. Figure 2 illustrates ADKAR model and the 5 simple phases of a workplace transformation and fit-out project overlapped with Kubler Ross Change Curve Model to apply them to the Smart Workplace Transformation project.

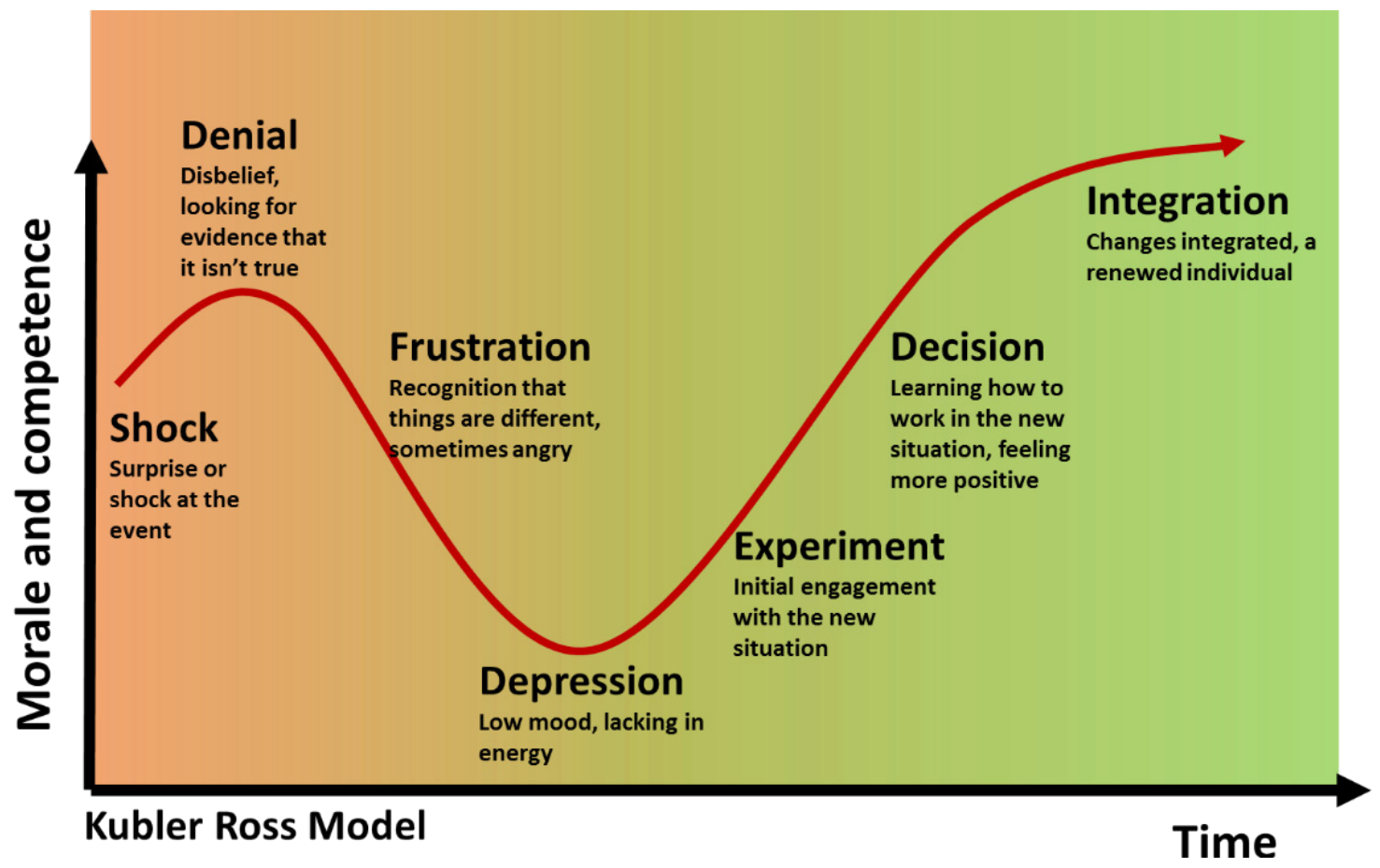

Figure 1. Kubler-Ross Change Curve Model 

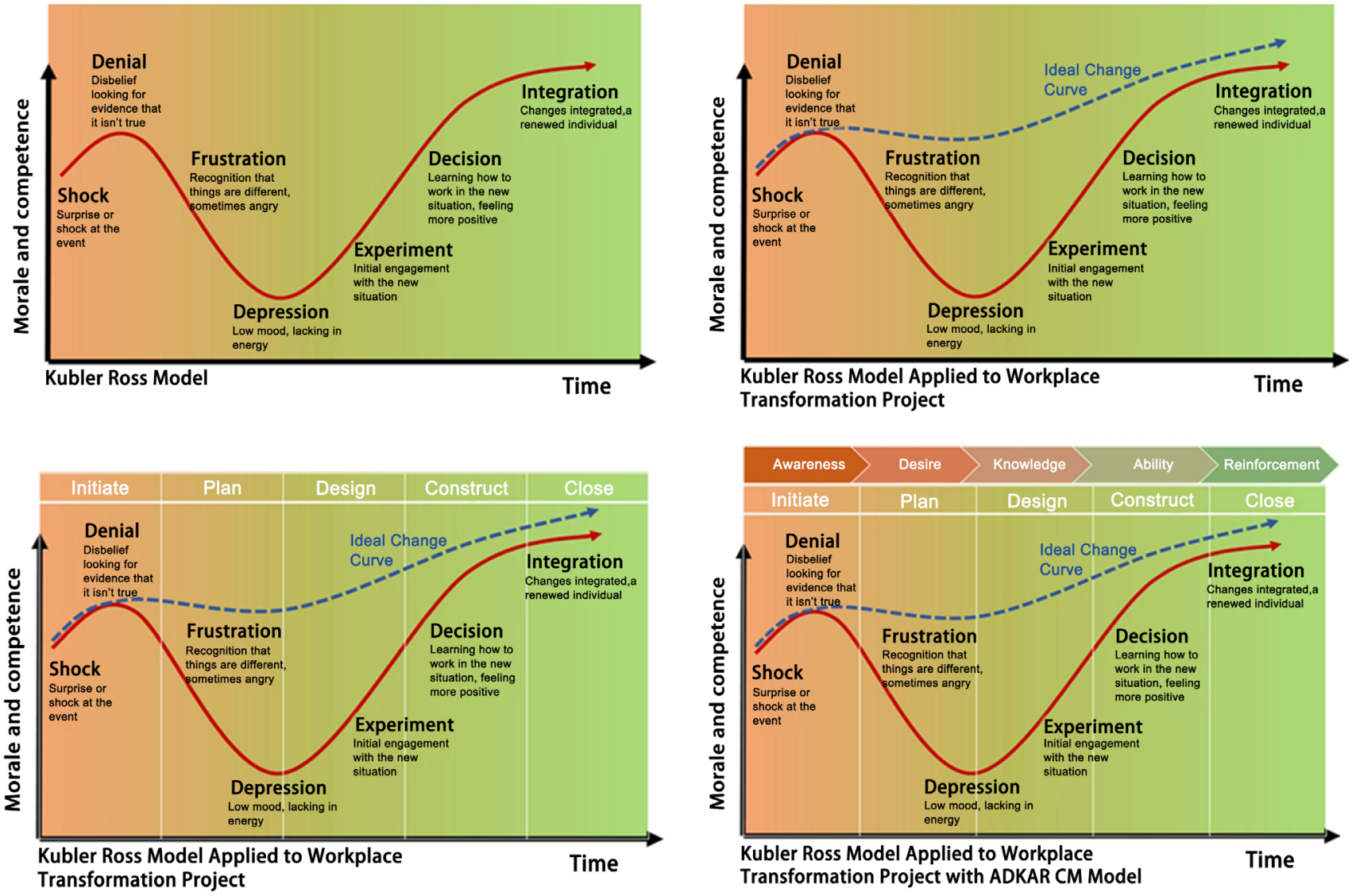

Figure 2. Kubler Ross Change Curve Model applied to Smart Workplace Transformation (Developed by Author)

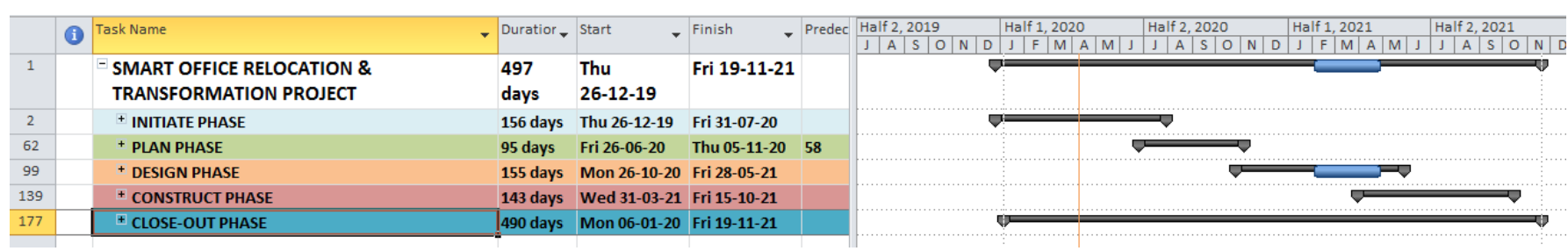

Figure 3. Phases and summary tasks of a Digital Workplace Transformation project program. Subtasks are collapsed due to the size of the program. (Developed by Author) 


\subsection{Methodology}

In order to achieve the objectives of the study, a focus group method has been used. However, in order to conduct the focus group session, the framework of the model has been adapted. This framework is based on the model explained in the Change Management section of this study, which consists of the integration of ADKAR Change Management model with Kubler Ross Change Curve Model and with the 5 basic phases of a fit-out project as illustrated in Figure 2.

For integration purposes, the main project schedule is based on a real-life example of comprehensive office relocation and a smart workplace transformation project schedule. The project schedule has been prepared in
Microsoft Project. The schedule for each phase of the project has been highlighted in a different color in Figure 3.

Including the real estate market search period, all process is anticipated to take approximately 500 days. The duration of the project hasn't been considered as a challenging area and optimization of the schedule could be an area for a future study.

Following the creation of the main project schedule, change management activities have been identified for each phase in accordance with ADKAR milestones which need to be achieved at each phase. These change management activities and their purposes have been illustrated in Figure 4. In order to integrate the change management activities with the work program, the focus group interview has been organized.

\begin{tabular}{|c|c|c|}
\hline Phase & Activity & Purpose \\
\hline \multirow{7}{*}{ 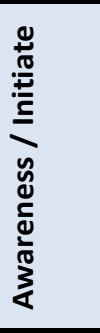 } & Leadership Engagement & Communicate Need for Digital Workplace \& Change Management \\
\hline & $\begin{array}{l}\text { Awareness for Leadership about the } \\
\text { DWP project management process }\end{array}$ & $\begin{array}{l}\text { Provide awareness to leadership team on how the DWP project shall be } \\
\text { managed }\end{array}$ \\
\hline & Develop Basic CM Plan & Define Key stages \& activities, success criteria \\
\hline & Utilization Study & To determine current use of the workplace, tools \& equipment \\
\hline & Employee work pattern survey & Understanding current work pattern and DW requirements \\
\hline & IT Systems Assessment & Evaluation of current IT systems platforms \& tools and GAP analysis \\
\hline & Employee Town Hall & Communication with Employees creating initial awareness Engagement \\
\hline \multirow{9}{*}{$\frac{\frac{5}{0}}{\frac{0}{0}}$} & Key Stakeholder Engagement & Involve Leadership team for each stage of the project \\
\hline & $\begin{array}{l}\text { Select and Onboard Change } \\
\text { Champions }\end{array}$ & $\begin{array}{l}\text { Selection of the OCC team to engage/ onboard on R\&R ad project next } \\
\text { steps }\end{array}$ \\
\hline & Employee Engagement & Employee engagement to the project \\
\hline & $\begin{array}{l}\text { Employee Envisioning / Deep dive } \\
\text { about DWP }\end{array}$ & Share potential changes, benefits and uses of DWP with employees \\
\hline & Onboard Change Champions & Onboarding Change Champions for their role \\
\hline & Deployment of survey results & Identify organization's needs \\
\hline & Benchmark & Discover best practices in the market and benchmark \\
\hline & Employee Envisioning Surveys & Collect feedback from employees about their dream workplace \\
\hline & Define Vision & Definition of vision \\
\hline \multirow{6}{*}{$\begin{array}{l}\text { ò } \\
\frac{0}{0} \\
\frac{0}{3} \\
\frac{0}{30} \\
0 \\
\frac{5}{5} \\
\frac{5}{0}\end{array}$} & Scope Definition Meetings & $\begin{array}{l}\text { What and How would be the new workplace setup } \\
\text { Special needs by organization }\end{array}$ \\
\hline & Communication Plan Announcement & Kick-off engagement of the organization \\
\hline & Setup Communication Tools & Special mail address, Newsletter \\
\hline & Design Activities & Action Plan definition with Main initiatives, Positive campaign \\
\hline & Design IT and Technologic Tools & Design the tools, equipment, systems, platforms \\
\hline & Design Review Meetings & Review designs with teams \\
\hline \multirow{5}{*}{ 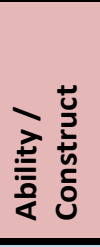 } & Setup Communication Tools & Special mail address, Newsletter \\
\hline & Cultural Interventions & Go Digital (Paperless), Digital Trainings, Move Training \\
\hline & Welcome Pack & $\begin{array}{l}\text { Provide a welcome kit for engagement and also with needed } \\
\text { information to a smooth transitions }\end{array}$ \\
\hline & Implement IT Systems & Implementation of IT systems \& platforms \\
\hline & Move Day Activities & Develop Plan for move day organization \\
\hline \multirow{5}{*}{ 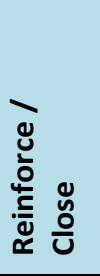 } & Learnings and Critical points & Identify key learnings \& action plans \\
\hline & Post Move Survey & Measure employee satisfaction \\
\hline & Hypercare for new tools \& equipment & Support employees for the new system \& tools \\
\hline & $\begin{array}{l}\text { Reinforce messages \& Make it } \\
\text { sustainable }\end{array}$ & Start Operation \& Continue Reinforcing messages, \\
\hline & $\begin{array}{l}\text { CM toolkit for Continuous Development } \\
\text { \& Onboarding }\end{array}$ & $\begin{array}{l}\text { Toolkit developed for future onboarding of new employees and new } \\
\text { leaders }\end{array}$ \\
\hline
\end{tabular}

Figure 4. Change Management activities identified for Digital Workplace Transformation (Developed by Author) 


\subsection{Focus Group Study}

Focus group method has been an increasingly popular qualitative research method not only in academia, but also in business as well [24]. The focus group has been defined by Krueger and Casey [25] as 'a carefully planned series of discussions designed to obtain perceptions on a defined area of interest in a permissive, non-threatening environment'. The use of the method dates back to mid-1920's however, it has become more popular within the last 20-30 years [26]. This is because the focus group method provides advantages such as;

- Being an efficient way of collecting a large amount of data in a short time $[25,26,27]$

- Ability to collect particular opinions, attitudes or different perspectives of participants [28]

- Ability to enable the researcher to attain in-depth insights into the researched topic [27]

- Ability to obtain information about their expert opinion from the participants

Therefore, the focus group method has been identified as the most suitable method for this study in order to obtain expert opinion on the identification and integration of change management activities.

Another important point in the focus group method is the size of the group. In his research, Masadeh [24] has reviewed and summarized suggestions of some authors and scientists and advised that the number of people in a focus group could be between 4 and 12 and in some cases, it could be even between 10 to 31 depending on the type and purpose of the study. In terms of the duration of the focus group session, Masadeh [24] also summarized the opinions of various researchers varying between 30 minutes to 3 hours.

It is obvious that the subject and the objectives of the research should be the main drivers determining the number of participants and the duration of the focus group session for the effectiveness of the study and quality of the data.

\section{Findings and Discussion}

In order to achieve the objectives of the Focus Group for this study and to collect reliable and quality data, 5 professionals have been identified and invited to a 1 hour 30 minutes session, who have been responsible for managing workplace fit-out projects, designs, facility management operations at multinational companies as well as managing the fit-out operation as general contractors, who have been involved in and experienced with workplace transformation and fit-out projects. Selected participants have also been involved in the change management activities in such projects. Therefore, all participants have experience with the subject. Therefore, participants of the focus group have been invited were;

- A Project Manager at a multinational real estate company,

- A Facility Manager of a multinational real estate company

- Workplace Designer \& Design Manager of a multinational real estate company

- General Manager of a contractor company whose expertise is fit-out and delivery of workplaces for multinational companies

- Construction Manager and Director of the same contractor company

Upon development of the detailed project schedule, the change management activities have been integrated with the project schedule as a draft version in order to use the time efficiently during the session. Figures 5-8 illustrate the part of the work schedule and the integrated Change Management (CM) activities. Then the focus group session has been organized where the author of this study acted as the moderator. Following the introduction, participants have independently shared their opinions and perspective on the project schedule, advised the CM activities for each phase, recommended necessary changes in sequence and timing of CM activities and any additional activities that might have been needed.

During the session, the participants have stressed the importance of implementing the change management process during a smart workplace transformation project especially involvement at the earliest stages of the project. This is because the important strategic decisions are made and communicated at the earlier stages and a structured change management program or strategy would significantly support the initial activities and increase the effectiveness of the transformation from the beginning. It has been also highlighted that employee engagement at the planning and design phase is very important in order to achieve buy-in of the employees. Getting the employee buy-in would significantly improve the success of the change management process therefore the success of the smart office transformation. 


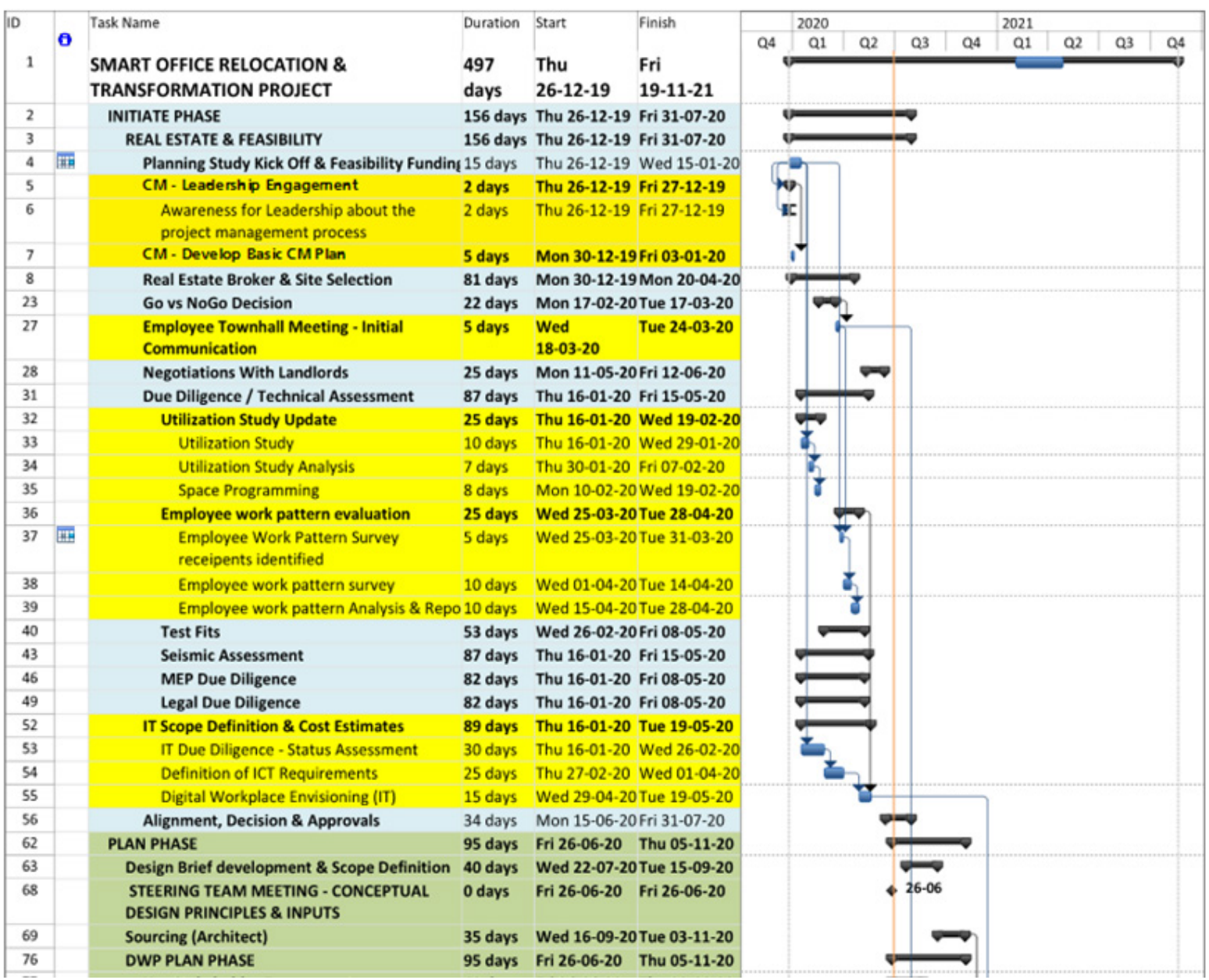

Figure 5. Change management activities integrated with project schedule - Summary of Activities 1-76 (by Author) 


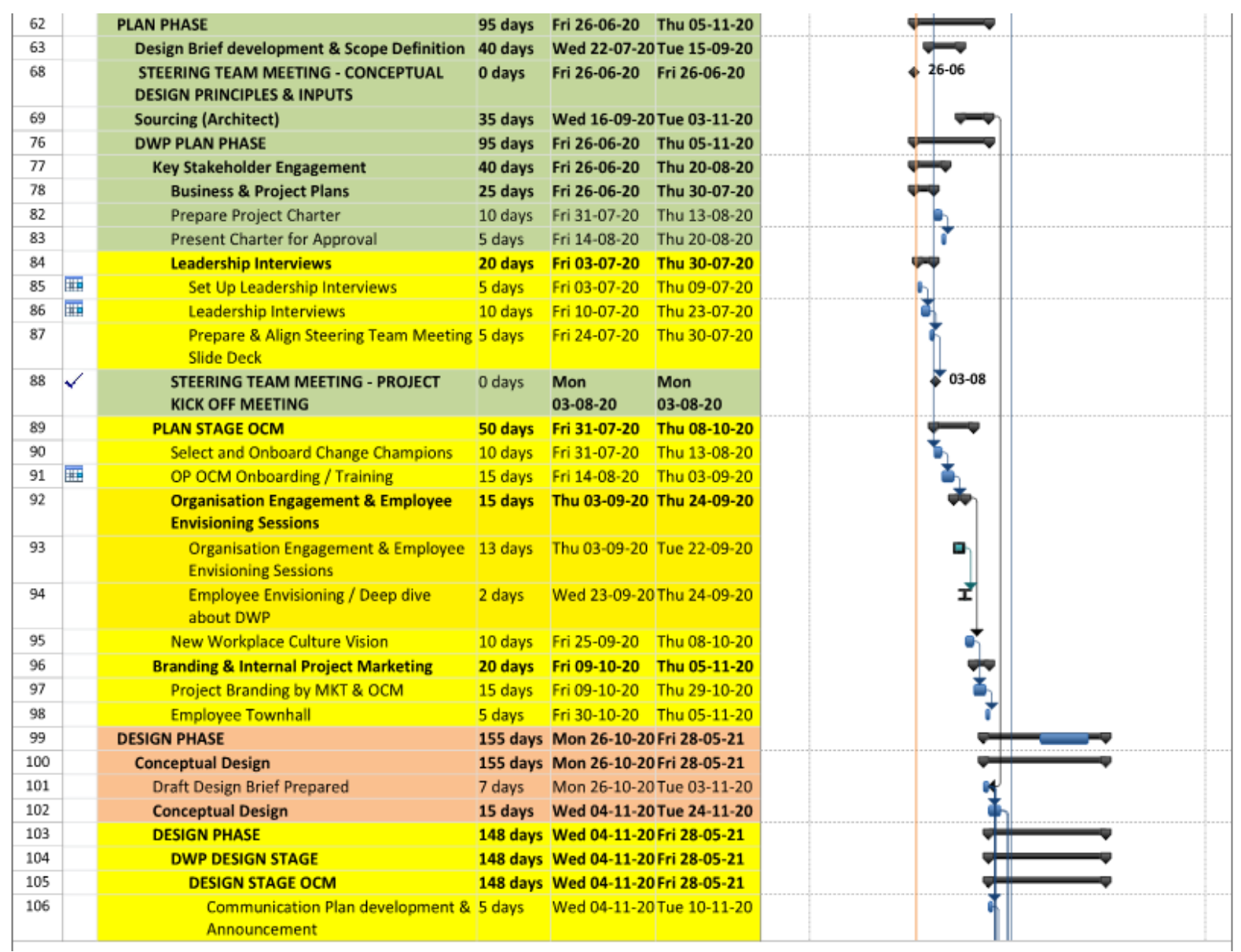

Figure 6. Change management activities integrated with project schedule - Summary of Activities 62-106 (by Author) 


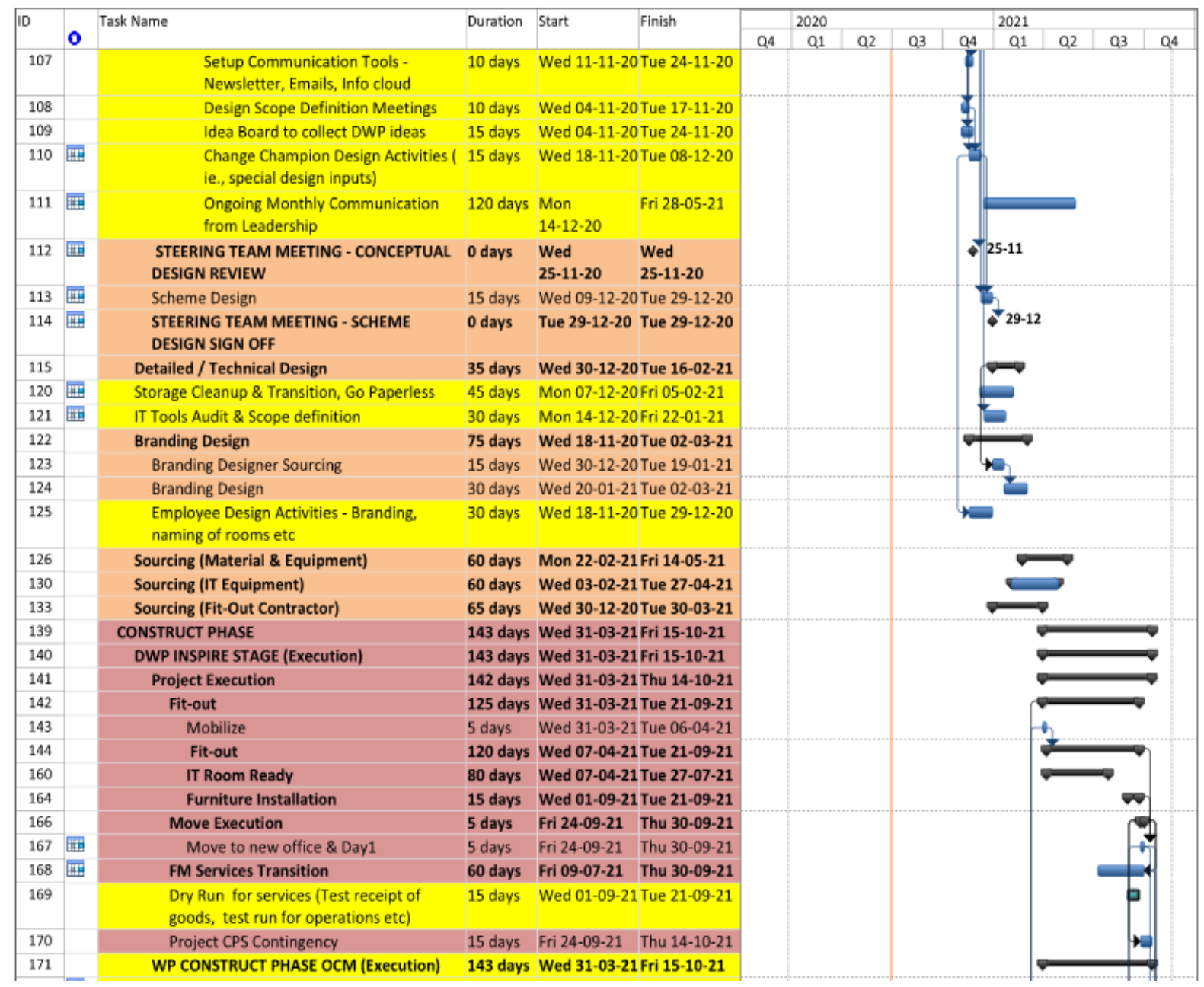

Figure 7. Change management activities integrated with project schedule - Summary of Activities 107-171 (by Author) 


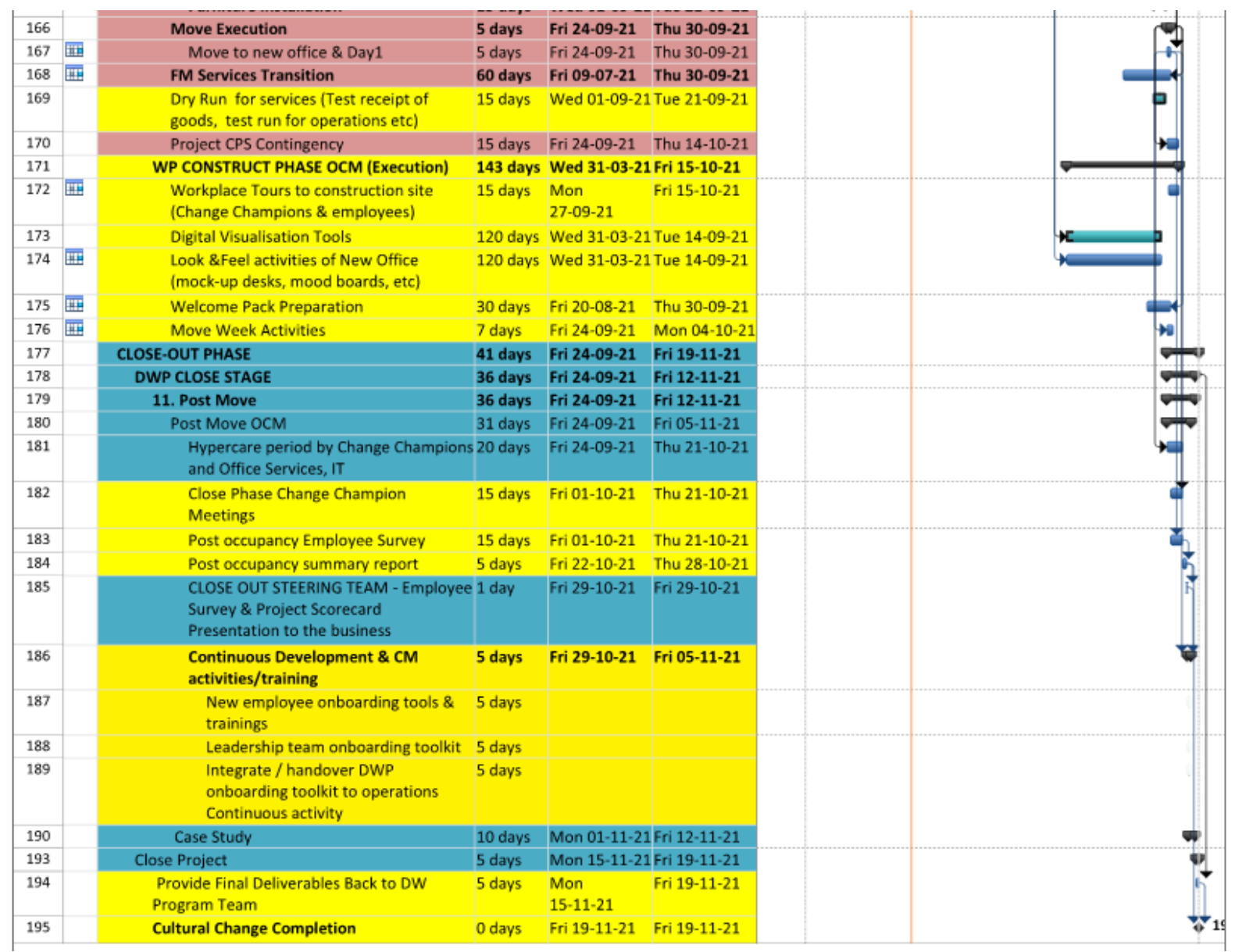

Figure 8. Change management activities integrated with project schedule - Summary of Activities 166-195 (by Author)

\section{Conclusions}

The processes and cultural change management activities may differ from one project to another depending on whether the project will be a workplace relocation or a transformation within the same premises. Also, the scope of the project, the number of process changes and the extent of the technology transformation and implementation will have an impact on the extent of the change management activities.

Although the cultural change management activities may be added or removed or shifted in between the phases, the model can be considered as a framework program for the smart workplace transformation project. The time spent on the activities may raise concerns in terms of the overall delivery date of the project, however, optimizing the duration needed for each activity may be another study area. On the other hand, focus group pointed out that if the Change Management activities start on a timely manner and are coordinated in parallel to the project activities, the time impact wouldn't be cause for concern and the benefits of implementing change management would exceed the cost or time impact. Further advice based on the experience has highlighted that successful implementation of the change management significantly increased the scores received from user experience surveys.

One of the most important outcomes of the focus group session has been the advice from the Facility Manager to implement the final phase of the change management process as an integral part of continuous development plans of the facilities operation. All projects need to be closed out once their lifecycle ends, however, it has been found out that the change management process should not end with the project closure and further $\mathrm{CM}$ activities should be part of the standard operating plans of the company to ensure the transformation is sustainable.

This initial report aims to provide the preliminary outcomes of the research. A forthcoming detailed report is anticipated to provide further details on the outcomes of the research and details of the model.

\section{Acknowledgements}

We are very grateful to the experts for their appropriate and constructive suggestions to improve this template and for the focus group participants for their contribution to 
the research.

The preliminary findings of this research have been presented at the 3rd International Conference of Contemporary Affairs in Architecture and Urbanism, ICCAUA 2020

This research did not receive any specific grant from funding agencies in the public, commercial, or not-for-profit sectors.

\section{Conflict of Interests}

The author declares no conflict of interest.

\section{REFERENCES}

[1] M. Attaran, S. Attaran, D. Kirkland. The Need for Digital Workplace: Increasing Workforce Productivity in the Information Age, International Journal of Enterprise Information Systems, Vol. 15, Iss. 1, January-March, 2019 https://doi.org/10.4018/IJEIS.2019010101

[2] M.L. Joroff, W.L. Porter, B. Feinberg, C. Kukla. The agile workplace, Journal of Corporate Real Estate, Vol.5(4), 293-311, 2003. https://doi.org/10.1108/1463001031081214 5

[3] M. A. Bell, M. Joroff. The Agile Workplace: Supporting People and Their Work, Gartner and Massachusetts Institute of Technology, 2001. Online available from https://books.g oogle.co.uk/books/about/The_Agile_Workplace.html?id=K fv4GgAACAAJ\&redir_esc $=\bar{y}$

[4] PWC. Millennials at work: Reshaping the workplace, Price Waterhouse Coopers, 2011. Online available from https://www.pwc.com/co/es/publicaciones/assets/millennial s-at-work.pdf

[5] B.P. Haynes. Office design for the multi-generational knowledge workforce, Journal of Corporate Real Estate. JCRE Vol. 13(4), pp. 216-232, November 2011. https://doi. org/10.1108/14630011111214428

[6] Deloitte. The digital workplace: think, share, do. Transform your employee experience, Deloitte Belgium, 2014. Online available from https://www2.deloitte.com/content/dam/Del oitte/be/Documents/technology/The_digital_workplace_Del oitte.pdf

[7] J. A. Robertson. Definition of the digital workplace ... and a journey, Step Two Designs Pty Ltd., 2015. Online available from https://www.steptwo.com.au/papers/digital-workplace -definition

[8] N.A.A. Bakar, S. Ya'acob, N.H. Hassan. Digital Workplace Model for Research University Publication Collaboration, International Journal of Human and Technology Interaction. Vol. 2 No. 2 October 2018. 91-101. eISSN: 2600-8122. Online available from https://www.researchgate.net/publica tion $/ 333825123$

[9] A.P. Williams, P. Schubert. Designs for the Digital Workplace, ProjMAN - International Conference on Project MANagement / HCist - International Conference on Health and Social Care Information Systems and Technologies,
CENTERIS/ProjMAN/HCist Elsevier 2018. https://doi.org/ 10.1016/j.procs.2018.10.066

[10] IBM. Digital workplace services for new ways of working, 2020. Online available from https://www.ibm.com/services/ digital-workplace

[11] Microsoft. Create your digital workplace with Microsoft Services, 2020. Online available from https://www.microso $\mathrm{ft.com/en-us/microsoftservices/campaigns/digital-workplac}$

[12] A. Pentland. How Social Networks Network Best, Harvard Business Review. February, 2009. 87(2), p 37. Online available from https://hbr.org/2009/02/breakthrough-ideas-f or-2009

[13] McKinsey. How companies are benefiting from Web 2.0: McKinsey Global Survey Results, McKinsey Quarterly. September, 2009. Online available from https://www.mckin sey.com/business-functions/mckinsey-digital/our-insights/h ow-companies-are-benefiting-from-web-20-mckinsey-glob al-survey-results

[14] Cisco. The Cisco Connected World Report. Cisco Systems. October, 2010. Online available from https://newsroom.cisc o.com/dlls/2010/ekits/ccwr_final.pdf

[15] Corporate Leadership Council (CLC). Driving Performance and Retention through Employee Engagement, 2004. Online available from https://www.stcloudstate.edu/humanr esources/_files/documents/supv-brown-bag/employee-enga gement.pd $\bar{d}$

[16] E. Lupfer. Social Technology \& an Innovative Intranet can Increase Employee Productivity, The Social Workplace, 2010. Online available from http://thesocialworkplace.com/ 2010/01/social-technology-an-innovative-intranet-can-incre ase-employee-productivity/

[17] Avanade. Global Survey: Companies are unprepared for the arrival of a true digital workplace. Online available from https://www.avanade.com/ /media/asset/point-of-view/digi tal-workplace-global-study.pdf?la=en-au?fsrc=eventsppusp ksocial

[18] M. Whittall. Flexible working environment can reduce absenteeism, European Foundation for the Improvement of Living and Working Conditions, 2007. Online available from https://www.eurofound.europa.eu/publications/article/ 2007/flexible-working-environment-can-reduce-absenteeis $\mathrm{m}$

[19] T.J.M. Van der Voordt. Costs and benefits of flexible workspaces: work in progress in The Netherlands, Facilities. September 2004, Volume 22, No. 9/10, 240-246. https://doi. org/10.1108/02632770410555959

[20] R. Fry. Millennials are the largest generation in the U.S. labor force, Pew Research Center, 2018. Online available from https://www.pewresearch.org/fact-tank/2018/04/11/mi llennials-largest-generation-us-labor-force/

[21] E. Kübler-Ross. On Death and Dying. Routledge, 1969. ISBN 0-415-04015-9

[22] Prosci. Definition of Change Management, 2020. Online available from https://www.prosci.com/resources/articles/c hange-management-definition

[23] J. Hiatt, T. Creasey. Change Management, The People Side of Change, Prosci Learning Center Publications 2012. ISBN: 
978-1-930885-61-5. Online available from https://www.aca demia.edu/32321746/Change_Management_The_People_Si de_of_Change_An introduction to change management $\mathrm{f}$ rom_the_editors_of_the_Change_Management_Learning Center?auto $=$ download

[24] M. A. Masadeh. Focus Group: Reviews and Practices. International Journal of Applied Science and Technology, Vol. 2 No. 10, December 2012. Online available from http://www.ijastnet.com/journal/index/378

[25] R.A. Krueger, M.A. Casey. Focus Groups: A Practical Guide for Applied Research, 4th ed. Thousand Oaks, CA. Sage Publications, 2009. ISBN: 978-1-4129-6947-5
[26] P. Liamputtong. Focus Group Methodology, Principles and Practice, Sage Publications, 2011. ISBN:978-1-84787-908-0

[27] C. W. Barrows. An exploratory study of food and beverage training in private clubs, International Journal of Contemporary Hospitality Management, 2000. Vol. 12(3), 190-197 https://doi.org/10.1108/09596110010320751

[28] T. Hines. An evaluation of two qualitative methods (focus group interviews and cognitive maps) for conducting research into entrepreneurial decision making, Qualitative Market Research, 2000, Vol. 3 No. 1, pp. 7-16. https://doi.o $\mathrm{rg} / 10.1108 / 13522750010310406$ 